\title{
$\mathrm{HEVC} \mathrm{RExt} \mathrm{RGB} \mathrm{영상의} \mathrm{색평면} \mathrm{간} \mathrm{예측} \mathrm{향상을} \mathrm{위한} \mathrm{적응적} \mathrm{필터링}$ 기법
}

\author{
최 장 원 ${ }^{a)}$ 최 윤 식 ${ }^{a \ddagger}$
}

\section{An Adaptive Filtering Method for Enhancement of Inter-color Plane Estimation in HEVC RExt RGB Images}

\author{
Jangwon Choi ${ }^{\text {a)}}$, and Yoonsik Choe ${ }^{\text {a) }}$
}

\section{요 약}

HEVC RExt(High Efficiency Video Coding Range Extension)는 RGB/YUV 4:2:2 4:4:4 색 샘플링 영상과 10비트 심도 이상의 영 상 지원을 목표로 한다. RGB 영상은 YUV 4:2:0 색 샘플링 영상과는 달리 색평면 간 높은 상관도를 갖고 있으며, 이를 이용하여 화소 값을 예측하는 기법들이 JCT-VC 표준화 회의에서 기고되었다. 하지만 일반적으로 RGB 영상의 고주파수 성분은 색평면 간 낮은 상관 도를 갖고 있으며, 이는 색평면 간 예측 시 부호화 효율 저하의 원인이 된다. 따라서 본 논문에서는 색평면 간 예측 시 고주파수 성분 을 저역통과필터를 통해 적응적으로 제거하는 기법을 제안한다. HEVC RExt의 RGB 영상을 통한 실험 결과, 본 논문에서 제안하는 기 법은 기존 색평면 간 예측 기법에 비해 큰 복잡도의 증가 없이 평균 $0.6 \%$ 의 $\mathrm{BD}(\mathrm{Bjontegaard} \mathrm{Distortion)-율} \mathrm{이득을} \mathrm{얻을} \mathrm{수} \mathrm{있었다.}$

\section{Abstract}

HEVC RExt(High Efficiency Video Coding Range Extension) set a goal to support RGB/YUV 4:2:2 4:4:4 color sampling and over 10 bit-depth images. Unlike the previous 4:2:0 color sampling images, RGB images have the high correlation in inter-color planes. Using this characteristic, some methods which are contributed in JCT-VC standardization meetings estimate the pixel values of inter-color plane. But when we use the estimation of inter-color plane in RGB images, high frequency components of RGB images are caused to reduce the coding efficiency because they usually have the low inter-color plane correlation. Therefore, in this paper, we propose an adaptive low pass filtering method in the inter-color plane estimation. Using this method, we can improve the estimation efficiency of inter-color plane in RGB images. The experimental results with HEVC RExt RGB test sequences show that the proposed method has $0.6 \% \mathrm{BD}$ (Bjontegaard Distortion)-rate gain and some increased complexity compared to the previous inter-color plane estimation method.

Keyword : HEVC RExt, RGB, extended chroma mode, inter-color correlation, adaptive filtering

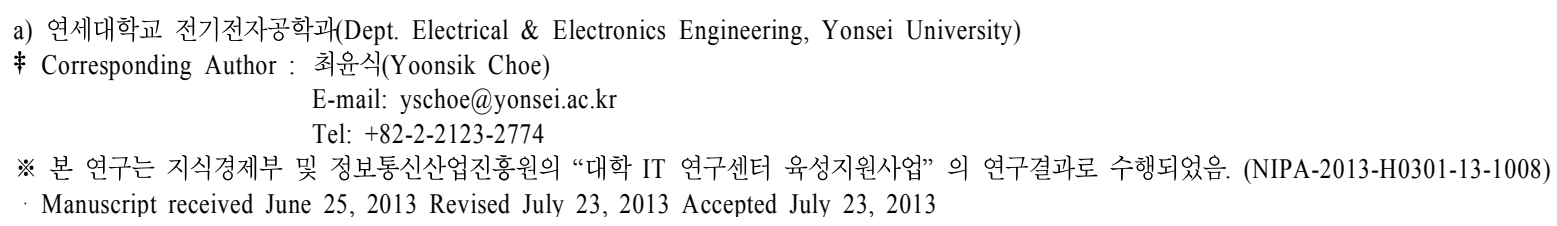




\section{I. 서 론}

최근 $\mathrm{HEVC} \mathrm{RExt}$ 가 $\mathrm{HEVC}^{[1]}$ 의 뒤를 이어 JCT-VC (joint collaborative team on video coding) 회의에서 표준화 진행 중에 있다. YUV 4:2:0 색 샘플링 및 10비트 심도 이하의 영상을 목표로 하는 $\mathrm{HEVC}$ 와는 달리, HEVC RExt에서는 $\mathrm{RGB} / \mathrm{YUV}$ 4:2:2 4:4:4 색 샘플링 및 10비트 심도 이상의 영상 지원을 목표로 한다마. 기존 4:2:0 색 샘플링 영상과는 달리 4:2:2, 4:4:4 색 샘플링 영상은 색평면 간 높은 상관도 (correlation)를 갖고 있으며, 이러한 높은 상관도를 이용하 여 부호화 효율을 높이기 위한 기술들이 최근 JCT-VC 회 의에서 논의되고 있다. 이중 ECM (extended chroma mode) 방법은 채도(chroma) 영역의 화면 내 예측(intra prediction) 시 부호화가 완료된 휘도(luma) 영역의 화소 정보를 이용하 여 색평면 간 예측을 수행하는 기술로 ${ }^{[3]}$, 색평면 간 상관도 가 높은 RGB 영상에서 높은 부호화 이득율(coding gain)을 보여준다. 하지만 일반적으로 RGB 영상의 고주파수 성분 은 저주파수 성분에 비해 색평면 간 상관도가 낮기 때문에 ${ }^{[4]}$, 이로 인해 $\mathrm{ECM}$ 을 이용한 색평면 간 예측 시 휘도 영역 의 고주파수 성분이 채도 영역의 화소 예측에 방해가 된다.

이에, 본 논문에서는 $\mathrm{ECM}$ 을 이용한 RGB 영상의 색평면 간 예측 시 예측 정확도를 높이기 위하여 화면 내 색평면 간 상관도가 낮은 휘도 영역의 고주파수 성분을 필터링을 통해 적응적으로 제거하는 방법을 제안한다.

\section{ECM (extended chroma mode)}

$\mathrm{ECM}$ 는 채도 영역의 화면 내 예측 시, 부호화가 완료된 휘도 영역의 화소값을 이용하여 채도 영역의 화소 값을 예 측하는 기법으로 ${ }^{[3]}$, 이 기법을 통해 색평면 간 상관도가 높 은 RGB 영상에서 월등한 부호화 이득율을 얻을 수 있다. $\mathrm{ECM}$ 은 채도의 화면 내 예측 모드에 추가되며, 기존의 화면 내 예측 방법과의 경쟁을 통해 선택되어진다.

$\mathrm{RGB}$ 영상은 $\mathrm{GBR}$ 순으로 부호화가 진행되기 때문에, B 또는 R 색평면은 채도의 화면 내 예측모드로 부호화 된다. 식 (1)은 RGB 영상에서의 ECM 방법을 보여준다.

$$
C_{\text {pred }}[x, y]=\alpha G_{\text {recon }}[x, y]+\beta
$$

여기서 $C_{p r e d}$ 는 예측하고자 하는 B 또는 R 블록의 화소 값을, $G_{r e c o n}$ 은 부호화가 완료된 $\mathrm{G}$ 블록의 복호화된 화소 값을, $[x, y]$ 는 화소의 위치를 의미한다. $\alpha$ 와 $\beta$ 는 가중치 값으로, 부호화 하고자 하는 B 또는 R 블록 주변의 화소값 과 동 위치의 $\mathrm{G}$ 화소 값들을 이용하여 유추할 수 있다.

\section{III. 제안하는 기법}

일반적으로 RGB 영상은 고 주파수 영역에서 색평면 간 낮은 상관도를 갖는다 ${ }^{[4]}$. 이를 확인하기 위해, 본 논문에서 는 주파수 분석 방법 ${ }^{[5]}$ 을 이용하여 현재 HEVC RExt에서 사용하고 있는 RGB 실험 영상들의 주파수 영역 별 색평면 간 상관도를 계산하였다. 표 1 은 몇몇 $\mathrm{RGB}$ 영상들의 첫 번째 장면(frame)을 이용하여 $\mathrm{G} / \mathrm{B} \mathrm{G} / \mathrm{R}$ 색평면 간 4 개의 주 파수 밴드(frequency band)의 상관도를 보여준다. 여기서 $\mathrm{LL}$ 주파수 밴드는 영상의 저주파수 성분을 의미하며, $\mathrm{LH}$ 및 $\mathrm{HL}$ 주파수 밴드는 영상의 수평 및 수직 에지(Edge) 성 분을 의미하며, $\mathrm{HH}$ 주파수 밴드는 영상의 대각선 에지 성 분을 의미한다. 표 1 을 보면 RGB 영상들이 LL 주파수 밴 드에서는 평균 0.90 의 높은 상관도를, $\mathrm{HH}$ 주파수 밴드에서 는 평균 0.38 의 낮은 상관도를 갖고 있음을 확인할 수 있다. 이 실험 결과를 기반으로, 본 논문에서는 RGB 영상의 색평 면 간 예측 효율을 높이기 위해 상관도가 낮은 고주파수 성분을 복호화된 $\mathrm{G}$ 색평면에서 제거하는 방법을 제안한다. 즉 $\mathrm{B}$ 또는 $\mathrm{R}$ 색평면에서 $\mathrm{ECM}$ 을 이용한 화면내 예측 부호 화 시, 다음 식(2)와 같이 저역통과필터를 통해 복호화된 $\mathrm{G}$ 색평면의 고주파수 성분을 제거한다.

$$
\begin{aligned}
C_{\text {pred }}[x, y]=\alpha & \alpha G_{\text {recon }}^{l p f}[x, y]+\beta \\
G_{\text {recon }}^{l p f}[x, y]= & 0.5 G_{\text {recon }}[x, y]+0.125 G_{\text {recon }}[x+1, y]+ \\
& 0.125 G_{\text {recon }}[x-1, y]+0.125 G_{\text {recon }}[x, y+1 \\
& 0.125 G_{\text {recon }}[x, y-1]
\end{aligned}
$$

여기서 $\alpha$ 와 $\beta$ 는 기존 $\mathrm{ECM}$ 에서와 같은 방법을 통해 얻 을 수 있으며, $G_{r e c o n}^{l p f}$ 값은 주변 4개의 화소 값을 이용하여 저역통과필터를 적용한 결과이다.

하지만 RGB 영상은 화면 내 영역 간에도 색평면 간 서로 
표 1. HEVC RExt RGB 실험 영상의 주파수 밴드별 색평면 간 상관도

Table 1. Inter-plane correlation in four subband of RGB test sequence of HEVC RExt

\begin{tabular}{|c|c|c|c|c|c|c|c|c|}
\hline \multirow{2}{*}{ Test sequence } & \multicolumn{3}{|c|}{$\mathrm{G} / \mathrm{B}$} & \multicolumn{4}{|c|}{$\mathrm{G} / \mathrm{R}$} \\
\cline { 2 - 9 } & $\mathrm{LL}$ & $\mathrm{LH}$ & $\mathrm{HL}$ & $\mathrm{HH}$ & $\mathrm{LL}$ & $\mathrm{LH}$ & $\mathrm{HL}$ & $\mathrm{HH}$ \\
\hline Traffic & 0.926 & 0.634 & 0.614 & 0.549 & 0.963 & 0.837 & 0.810 & 0.777 \\
\hline Kimono1 & 0.948 & -0.105 & 0.136 & -0.008 & 0.977 & -0.011 & 0.303 & 0.045 \\
\hline EBULupoCandlelight & 0.820 & 0.859 & 0.869 & 0.899 & 0.904 & 0.944 & 0.929 & 0.940 \\
\hline EBURainFruits & 0.909 & 0.972 & 0.970 & 0.955 & 0.892 & 0.971 & 0.969 & 0.956 \\
\hline VenueVu & 0.720 & 0.885 & 0.853 & 0.553 & 0.597 & 0.840 & 0.604 & 0.229 \\
\hline DucksAndLegs & 0.906 & 0.227 & -0.090 & -0.154 & 0.963 & 0.238 & 0.125 & -0.186 \\
\hline OldTownCross & 0.981 & 0.456 & 0.265 & 0.025 & 0.984 & 0.617 & 0.466 & 0.243 \\
\hline ParkScene & 0.919 & 0.247 & 0.443 & 0.117 & 0.972 & 0.406 & 0.462 & 0.126 \\
\hline Overall & 0.891 & 0.522 & 0.508 & 0.367 & 0.907 & 0.605 & 0.584 & 0.391 \\
\hline
\end{tabular}

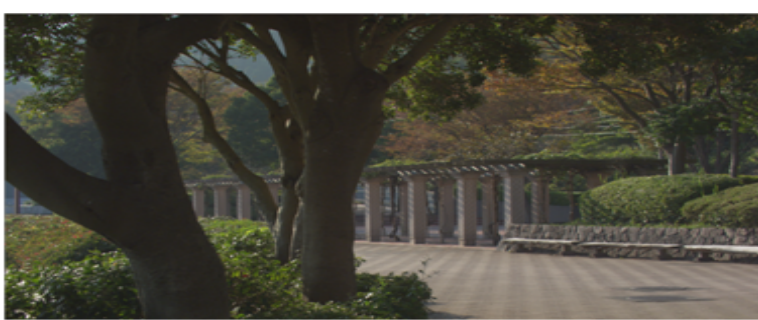

(a)

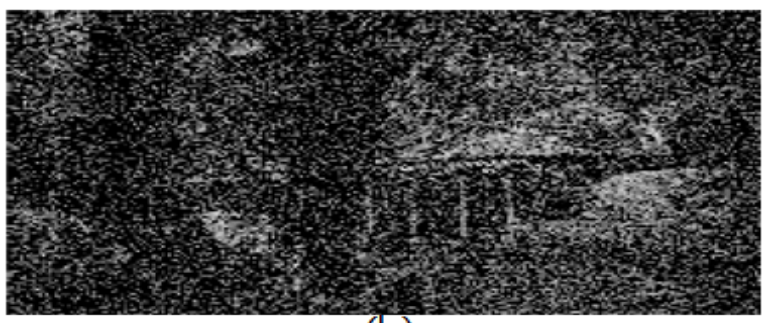

(b)

그림 1. ParkScene RGB 영상에서 색평면 간 고주파수 성분의 화면 내 상관도 (a) 원 영상 (b) G/B 색평면 간

Fig. 1. Intra correlation of inter color plane high frequency component in ParkScene RGB sequence (a) original color image (b) G/B inter color plane

다른 상관도를 보인다. 그림 1은 ‘ParkScene' RGB 실험영 상의 첫 장면에서 화면 내 고주파수 성분의 색평면 간 상관 도 분포를 나타낸다. 그림 1(b)는 $\mathrm{G} / \mathrm{B}$ 색평면 간 고주파수 성분의 상관도를 $8 \times 8$ 블록 단위로 계산한 결과를 보여주며, 그림에서 블록 영역의 밝기가 밝을수록 높은 상관도를, 어 두울수록 낮은 상관도를 의미한다. 이를 보면 RGB 영상의 화면 내에서도 색평면 간 상관도가 높은 영역과 낮은 영역 이 동시에 존재하며, 따라서 제안하는 필터링 기법의 성능 극대화를 위해서는 고주파수 성분의 색평면 간 상관도가
낮은 영역에만 필터링을 적용하는 기법이 요구된다. 이에 본 논문에서는 $\mathrm{ECM}$ 시 복호화된 $\mathrm{G}$ 색평면에 $\mathrm{LPF}$ 를 적용 하는 모드를 채도의 화면 내 예측에 추가하였다. 즉, 기존의 화면 내 예측 모드 및 $\mathrm{ECM}$, 그리고 제안하는 기법 사이의 모드 경쟁을 통해 최적의 화면 내 예측 모드가 선택될 수 있도록 하였으며, 이를 통해 화면 내 고주파수 성분의 색평 면 간 상관도 변화에 적응적인 필터링이 가능하게 되었다.

\section{IV. 실험 및 결과}

본 논문에서 제안하는 기법의 성능 검증을 위해, 기존 $\mathrm{ECM}$ 과의 부호화 및 복호화 성능 결과를 비교하였다. 이를 위해 HEVC RExt에서 사용하고 있는 8개의 RGB 실험 영 상 및 공동 실험 환경에 따라 부호화 및 복호화 실험을 진행 하였다 ${ }^{[6]}$. HM10.0_RExt2.0 소프트웨어를 기반으로 화면 내 예측에서 사용하는 $\mathrm{ECM}$ 특성 상 $\mathrm{AI}($ all intra) 실험 조건 을 이용하였으며, QP는 $12,17,22,27$ 을 사용하였다.

앞서 말한바와 같이 채도의 화면 내 예측 모드에 제안하 는 필터링 기법을 추가하였으며, 이를 위한 2 진화는 표 2 와 같이 구현하였다. 기존에는 ECM 모드 시 prefix ' 10 ' 비트 만을 모드 부호화 시 사용하였지만, 본 논문에서 제안하는 알고리즘 추가를 위해, ECM 모드 및 제안하는 모드에 prefix '10'비트 및 추가로 suffix 1비트를 사용하였다.

표 3 은 $\mathrm{ECM}$ 을 레퍼런스로 하였을 때의 제안하는 기법의 성능 결과를 보여준다. 결과를 살펴보면, 제안하는 기법은 $\mathrm{ECM}$ 에 비해 $\mathrm{G}, \mathrm{B}, \mathrm{R}$ 색평면에서 평균 $0.4 \%, 0.6 \%, 0.8 \%$ 
표 2. 제안하는 기법을 위한 chroma_pred_from_luma_enable_flag에 따른 intra_chroma_pred_mode의 명시법

Table 2. Specification of intra_chroma_pred_mode on chroma_pred_from_luma_enable_flag for the proposed method

\begin{tabular}{|c|c|c|c|c|}
\hline \multirow{2}{*}{ intra_chroma_pred_mode } & \multicolumn{2}{|c|}{$\begin{array}{c}\text { chroma_pred_from } \\
\text { luma_enabled_fla } \\
\mathrm{g}=1\end{array}$} & \multicolumn{2}{c|}{$\begin{array}{c}\text { chroma_pred_from } \\
\text { luma_enabled_fla } \\
\mathrm{g}=0\end{array}$} \\
\cline { 2 - 5 } & prefix & suffix & prefix & suffix \\
\hline 6 (DM_CHROMA) & 0 & $\mathrm{n} / \mathrm{a}$ & $\mathrm{n} / \mathrm{a}$ & $\mathrm{n} / \mathrm{a}$ \\
\hline 5 (proposed method) & 10 & 1 & 0 & $\mathrm{n} / \mathrm{a}$ \\
\hline 4 (ECM) & 10 & 0 & 0 & $\mathrm{n} / \mathrm{a}$ \\
\hline 0 (PLANAR) & 11 & 00 & 1 & 00 \\
\hline 1 (VERTICAL) & 11 & 01 & 1 & 01 \\
\hline 2 (HORIZONTAL) & 11 & 10 & 1 & 10 \\
\hline 3 (DC) & 11 & 11 & 1 & 11 \\
\hline
\end{tabular}

표 3. 제안하는 기법의 $\mathrm{BD}$-율 이득 및 부호화복호화 복잡도

Table 3. The BD-rate gain and complexity of encoding/decoding of proposed method

\begin{tabular}{|c|r|r|r|c|c|}
\hline \multirow{2}{*}{ Test sequence } & \multicolumn{3}{|c|}{ BD-rate gain (\%) } & \multicolumn{2}{c|}{ Complexity (\%) } \\
\cline { 2 - 6 } & \multicolumn{1}{|c|}{ G } & \multicolumn{1}{c|}{ B } & R & encoding & decoding \\
\hline Traffic & 0.0 & -0.2 & -0.6 & 108 & 101 \\
\hline Kimono1 & -0.6 & -0.9 & -0.9 & 108 & 101 \\
\hline EBULupoCandlelight & -0.5 & -0.7 & -0.9 & 107 & 101 \\
\hline EBURainFruits & 0.6 & 0.0 & -0.5 & 107 & 101 \\
\hline VenueVu & -0.8 & -1.3 & -1.2 & 107 & 101 \\
\hline DucksAndLegs & -0.5 & -0.3 & -0.1 & 108 & 101 \\
\hline OldTownCross & -0.6 & -0.8 & -0.8 & 108 & 100 \\
\hline ParkScene & -0.7 & -0.9 & -0.9 & 108 & 100 \\
\hline Overall & -0.4 & -0.6 & -0.8 & 108 & 101 \\
\hline
\end{tabular}

의 $\mathrm{BD}$-율 이득을 보였다. 이를 통해 제안하는 필터링기법 이 색평면 간 예측 효율 증가에 효과적임을 확인하였다. 하 지만 EBURainFruits 실험 영상의 경우에는 $\mathrm{G}$ 색평면에서 $0.6 \%$ 의 $\mathrm{BD}$-율 손실을 보였다. 이는 표 1 에 보여지는 바와 같이 EBURainFruits 영상의 경우 모든 주파수 영역에서 색 평면 간 상관도가 높은 특성을 갖고 있기 때문에 제안하는 기법이 효과가 없음을 알 수 있으며, 오히려 모드 추가로 인한 모드 부호화 비트 증가로 인해 $\mathrm{BD}$-율 손실을 보였음 을 확인할 수 있다.

표 3을 보면 제안하는 기법의 부호화 복잡도는 $\mathrm{ECM}$ 과 비교시 평균 $8 \%$, 복호화는 평균 $1 \%$ 증가한 것을 볼 수 있 다. 특히 복잡도 증가에 가장 민감한 복호화 복잡도가 $1 \%$ 증가에 그쳤기 때문에 본 논문에서 제안하는 기법이 부호
화 및 복호화 복잡도에 큰 부담을 주지 않는 동시에 $\mathrm{BD}$-율 이득을 얻을 수 있음을 확인할 수 있었다.

\section{IV. 결론 및 향후 연구}

본 논문에서는 HEVC RExt에서 RGB 영상의 색평면 간 예측 시, 색평면 간 상관도가 낮은 고주파수 성분을 제거함 으로써 부호화 성능을 높이는 기법을 제안하였다. 또한 채 도의 화면 내 예측 모드에 본 논문에서 제안하는 필터링 기법을 추가함으로써 화면 내 고주파수 성분의 상관도 변 화에 대응하는 적응적인 필터링이 가능하게 하였다. $\mathrm{HEVC}$ $\mathrm{RExt}$ 의 RGB 실험영상을 통해 본 논문에서 제안하는 기법 의 성능을 검증하였으며, $\mathrm{ECM}$ 과의 비교시 평균 $0.6 \%$ 의 $\mathrm{BD}$-율 이득을 얻을 수 있었다. 또한 부호화 복잡도는 평균 $8 \%$, 복호화 복잡도는 평균 $1 \%$ 증가에 그쳤기 때문에, 본 논문에서 제안하는 기법이 HEVC RExt RGB 영상 압축에 효율적임을 확인하였다. 또한 향후에는 블록의 주변 정보 를 이용하여 현재 블록의 필터링 유무를 판단함으로써, 모 드 추가로 인한 모드 부호화 비트를 줄일 수 있는 방법에 대한 연구를 진행 할 계획이다.

\section{참 고 문 헌}

[1] G. Sullivan, J. Ohm, W. Han, and T. Wiegand, "Overview of the High Efficiency Video Coding (HEVC) Standard", IEEE Transactions on Circuits and Systems for Video Technology, Vol. 22, No. 12, Dec. 2012.

[2] D. Flynn, J. Sole, and T. Suzuki, "High Efficiency Video Coding (HEVC) Range Extensions text specification : Draft 2 (for PDAM)“, JCTVC-L1003, 12th JCT-VC Meeting, Geneva, Switzerland, Jan. 2013.

[3] J. Kim, "RCE1: The performance of extended chroma mode for non 4:2:0 format, JCTVC-M0097, 13th JCT-VC Meeting, Incheon, Korea, Apr. 2013

[4] Y. kim, B. Choi, and J. Paik, "High-Fidelity RGB Video Coding Using Adaptive Inter-Plane Weighted Prediction", IEEE Transactions on Circuits and Systems for Video Technology, Vol. 19, No. 7, Jul. 2009.

[5] B. Gunturk, Y. Altunbasak, and R. Mersereau, "Color plane interpolation using alternating projections", IEEE Transactions on Image Processing, Vol. 11, No. 9, pp. 997-1013, September 2002.

[6] D. Flynn, and C. Rosewarne, "Common test conditions and software reference configurations for HEVC range extensions", JCTVC-L1006, 12th JCT-VC Meeting, Geneva, Switzerland, Jan. 2013. 